Scientific Review - Engineering and Environmental Sciences (2020), 29 (2), 196-211

Sci. Rev. Eng. Env. Sci. (2020), 29 (2)

Przegląd Naukowy - Inżynieria i Kształtowanie Środowiska (2020), 29 (2), 196-211

Prz. Nauk. Inż. Kszt. Środ. (2020), 29 (2)

http://iks.pn.sggw.pl

DOI 10.22630/PNIKS.2020.29.2.17

Osama T. Al-TAAI, Zainab M. ABBOOD

Mustansiriyah University, College of Science

\title{
Analysis of the convective available potential energy by precipitation over Iraq using ECMWF data for the period of 1989-2018
}

Key words: convective precipitation, total precipitation, Spearman rho test, CAPE, ECMWF, Iraq

\section{Introduction}

The rain is the most common type of precipitation in our atmosphere and when liquid droplet falls to the earth surface. The source of precipitation is water vapor, which is always present in the atmosphere in varying amounts; there are three major types of rain can be distinguished depending on the different factors that cause the airlifting and formation of clouds and rain falling as well as meteorology factors (Niwas, Singh, Singh, Khichar \& Singh, 2006):

- Convectional rainfall: this type of rainfall occurs due to the ground surface heating. When the land warms up, it heats the air above it. This causes the air to expand and rise. As the air rises it cools and condenses. If this process continues then rain will fall. Convectional rainfall occurs for a very short duration but occurs in the form of heavy showers. This type of rain is often accompanied by lightning and thunder. It is called ascending/rising rain because it is the result of a rising process of the atmosphere, which is exposed to thermal heating and clouds resulting from this type cumulus and cumulonimbus (Saxena \& Gupta, 2017).

- Cyclonic/Frontal rainfall: this type of rainfall occurs when a warm and moist air mass (warm front) meets a cold and dry air mass (cold front). When both masses come together, warmer air is forced to rise over cold air. The moist warm air condenses as it cool, which causes cloud and rain. When there are condensation nuclei and when the atmosphere arrives at saturation 
ratio. Frontal rain produces a variety of clouds, which bring moderate to heavy rainfall. They are called with this name because they are formed by the collision of two air masses and clouds resulting from this type stratus, altostratus, cirrus, and cumulus (Goyal, 2016).

- Orographic rainfall: this type of rainfall occurs when moisture-laden air encounters a mountain range, the air is forced to rise. It cools off at the higher elevation and this condenses water out of the air and creates clouds and rains. If the temperature is cold enough, the precipitation falls as snow. It is called orographic rain because it is influenced by the terrain when falling. Clouds forms and precipitation occurs on the windward side of the mountain and another side of the mountain is called the leeward side, it receives very little precipitation and clouds resulting from this type stratus, altostratus and cumulus and occurs in the northern and northeastern regions (Ahrens, 2013; Lackmann, 2013), as shown in Figure 1 (Gabler, Petersen, Trapasso \& Sack, 2009).

\section{Literature review}

There many from studies to find the effect of rainfall on soil erosion for the selected station in Iraq and found when analyzing the monthly total rainfall for 18 years that rainfall varies according to the station height and geographic location as well as by months.

Where northern stations recorded the highest loss of the rain while south stations recorded the lowest loss of the rain and was the higher loss of rain during winter months (December, January and February) and was the lower loss of rain during summer months (Al-Obeidi, 2008). Some research showed that the highest rainfall was in the northern regions, especially in Sulaymaniyah station. The lowest rainfall was in Babil station for the period of 2000-2013. The amount of rainfall began to fluctuate and decrease during 2007 due to temperature variation (Salman, 2015). However, there a seasonal study of convective available potential energy (CAPE) is done using 6-h ERA-Interim data over West Africa during 35 years (1979-2014).

Climatology of CAPE presented in terms of seasonal means, variances and a

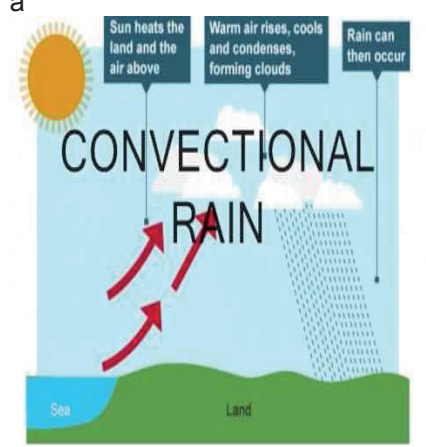

b

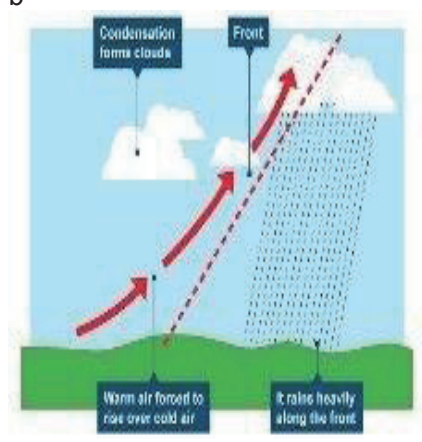

C

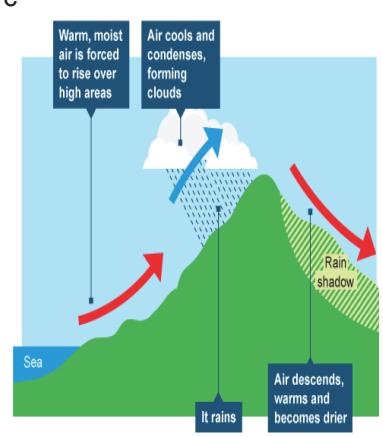

FIGURE 1. Rainfall: a - convectional, b - cyclonic/frontal, c - cyclonic (Gabler et al., 2009) 
trends shows large values toward $12^{\circ}$ $-16^{\circ} \mathrm{N}$ with maxima during summer, according to higher relative humidity due to the arrival of monsoon in West Africa (Meukaleuni, Lenouo \& Monkam, 2016). Also, their synoptic study of the role of convective available potential energy on formation rainstorm over Iraq and resulted in convectional precipitation coincides convective available potential energy this due to Low Mediterranean Sea and Low Sudanese and the northern regions of Iraq have the highest CAPE, followed by the central regions and southern regions, accompanied by the highest rainfall values (Namdar, 2017).

\section{Convective available potential energy (CAPE)}

CAPE is the amount of energy a given parcel of air would have if lifted a certain distance vertically through the atmosphere. CAPE is effectively the positive buoyancy of an air parcel and is an indicator of atmospheric instability, which makes it very valuable in predicting severe weather. It is a form of fluid instability found in thermally stratified atmospheres in which a colder fluid overlies a warmer one. An air mass will rise if it is less dense than the surrounding air (its buoyant force is greater than its weight). This can create vertically developed clouds due to the rising motion, which could lead to thunderstorms. It could also be created by other phenomena, such as a cold front. Even if the air is cooler on the surface, there is still warmer air in the mid-levels that can rise into the upper levels. However, if there is not enough water vapor present, there is no ability for condensation, thus storms, clouds, and rain will not form (Schultz, 1989; Riemann-Campe, Fraedrich \& Lunkeit, 2009). CAPE exists within the conditionally unstable layer of the troposphere, the free convective layer (FCL), where an ascending air parcel is warmer than the ambient air.

CAPE is measured in joules per kilogram of air. Any value greater than 0 $\mathrm{J} \cdot \mathrm{kg}^{-1}$ indicates instability and an increasing possibility of thunderstorms and hail. Often exceed the potential energy values in the thunderstorms $1,000 \mathrm{~J}^{\mathrm{kg}} \mathrm{kg}^{-1}$ and in extreme cases may exceed $5,000 \mathrm{~J} \cdot \mathrm{kg}^{-1}$. Generic CAPE is calculated by integrating vertically the local buoyancy of a parcel from the level of free convection (LFC) to the equilibrium level (EL):

$C A P E=\int_{Z_{f}}^{Z_{n}} \mathrm{~g}\left(\frac{T_{v_{p a r}}-T_{v_{e n v}}}{T_{v_{e n v}}}\right) d z$

whereas:

$Z_{n}$ - height of the equilibrium level,

$Z_{f}$ - height of the level of free convection,

$\mathrm{g}$ - acceleration due to gravity,

$T_{v_{p a r}}$ - virtual temperature of the specific parcel $\left[{ }^{\circ} \mathrm{K}\right]$,

$T_{v_{e n v}}$ - virtual temperature of the environment $\left[{ }^{\circ} \mathrm{K}\right]$ (Doswell III \& Rasmussen, 1994; Gettelman, Seidel, Wheeler \& Ross, 2002).

\section{Convective precipitation $\left(\mathrm{C}_{\mathrm{p}}\right)$}

Convective precipitation is also known as thermodynamic precipitation. While dynamic precipitation only needs saturated air and lift, convective precipi- 
tation requires an additional component called instability (Wang, 2013). Uplift due to instability release occurs when the air rises on its own after being lifted to a certain point in the troposphere. Instability is commonly assessed by examining the Lifted Index (LI) and CAPE. Both these indices can be used to assess the acceleration rate of air once air from the lower troposphere is brought to a level in the troposphere where it will rise on its own due to positive buoyancy. Instability causes the air to rise much faster than it would be forced lifting alone (Abbood \& Al-Taai, 2018a). Think of convective precipitation as falling from thunderstorms with strong updrafts while dynamic precipitation falls from a deck of stratus clouds. Convective precipitation tends to have lighting, thunder and heavy rain while dynamic precipitation is more of a gentle long-lasting rain with no lightning and thunder (Abbood \& Al-Taai, 2018b).

\section{Data and methodology}

\section{Study stations and location}

Data were taken from the European Center for Medium-range Weather Forecasts for monthly CAPE, $C_{p}$ and $T_{p}$ for 30 years, from 1989 to 2018 over Iraq. As Iraq is located within the arid and semi-arid region, it is characterized by variance rainfall between one year and another and this variation in the amount of rain has made there are years characterized by high quantities of general levels it is a wet year, and other decreases in the amount of rain it is a dry year (Zakaria, Al-Ansari, Ezz-Aldeen \& Knutsson, 2012). Iraq is located within the southwestern part of the continent of Asia. The northeastern part of the Arab world and extends between the two latitudes $29.5^{\circ}-37.22^{\circ} \mathrm{N}$ and longitudes $48.45^{\circ}-$ $-38.45^{\circ} \mathrm{E}$; it includes the following stations as in Table 1 (Al-Timimi, 2012), see Figure 2.

TABLE 1. The geographical locations of Iraqi stations (Al-Timimi, 2012)

\begin{tabular}{|l|c|c|c|}
\hline Station & Longitude $\left[^{\circ}\right]$ & Latitude $\left[^{\circ}\right]$ & Elevation $[\mathrm{m}]$ \\
\hline Emadiyah & 43.3 & 37.05 & 1236 \\
\hline Salahaddin & 44.2 & 36.38 & 1075 \\
\hline Sulaymaniyah & 45.45 & 35.53 & 843 \\
\hline Sinjar & 41.83 & 36.32 & 583 \\
\hline Dohook & 43 & 36.87 & 554 \\
\hline Zakho & 42.72 & 37.13 & 433 \\
\hline Arbil & 44 & 36.15 & 420 \\
\hline Rabiah & 42.1 & 36.8 & 382 \\
\hline Taleafer & 42.48 & 36.37 & 373 \\
\hline Kirkuk & 44.35 & 35.47 & 331 \\
\hline Nukheb & 42.28 & 32.03 & 305 \\
\hline Dukcan & 44.95 & 35.95 & 276 \\
\hline Sumeel & 42.75 & 36.87 & 250 \\
\hline
\end{tabular}


TABLE 1 cont.

\begin{tabular}{|c|c|c|c|}
\hline Station & Longitude $\left[{ }^{\circ}\right]$ & Latitude $\left[{ }^{\circ}\right]$ & Elevation $[\mathrm{m}]$ \\
\hline Mosul & 43.15 & 36.31 & 223 \\
\hline Rutba & 40.28 & 33.03 & 222 \\
\hline Tuz & 44.65 & 34.88 & 220 \\
\hline Khanqin & 45.38 & 34.35 & 202 \\
\hline Qaim & 41.02 & 34.38 & 178 \\
\hline Anah & 41.95 & 34.37 & 175 \\
\hline Biji & 43.53 & 34.9 & 116 \\
\hline Hadithah & 42.35 & 34.13 & 108 \\
\hline Tikrit & 43.7 & 34.57 & 107 \\
\hline Samaraa & 43.88 & 34.18 & 75 \\
\hline Heet & 42.75 & 33.63 & 58 \\
\hline Najaf & 44.32 & 31.95 & 53 \\
\hline Ramadi & 43.32 & 33.45 & 48 \\
\hline Kahalis & 44.53 & 33.83 & 44 \\
\hline Baghdad & 44.4 & 33.3 & 32 \\
\hline Kerbela & 44.05 & 32.57 & 29 \\
\hline Hella & 44.45 & 32.45 & 27 \\
\hline Makoor & 43.6 & 35.75 & 22 \\
\hline Kut & 45.75 & 32.49 & 21 \\
\hline Diwaniya & 44.95 & 31.95 & 20 \\
\hline Hai & 46.03 & 32.13 & 17 \\
\hline Samawa & 45.27 & 31.27 & 11 \\
\hline Amara & 47.17 & 31.83 & 9 \\
\hline Nasiriya & 46.23 & 31.02 & 5 \\
\hline Basrah & 47.78 & 30.52 & 2 \\
\hline
\end{tabular}

\section{Statistical used}

There were several statistical tests but selected Spearman rho tests for the order of this work has been selected regression analysis. In particular, the simple linear regression to predict the relationship between CAPE, $\mathrm{C}_{\mathrm{p}}$ and $\mathrm{T}_{\mathrm{p}}$ (Bolboaca \& Jäntschi, 2006; Hron, Filzmoser \& Thompson, 2012). Where used statistical program Sigma plot to calculate the value of the slope of the regres- sion (b) and the value of $p$-value simple linear regression way and Surfer program to graph total yearly mean of CAPE, $\mathrm{C}_{\mathrm{p}}$ and $T_{p}$ over Iraq and GIS to graph Iraq map (Padua, 2000; York, Evensen, Martinez \& Delgado, 2004) and statistical used represents in following equations:

- simple linear regression (SLR)

$\bar{Y}=a+b \bar{X}$

- Spearman rho test (SRT) 


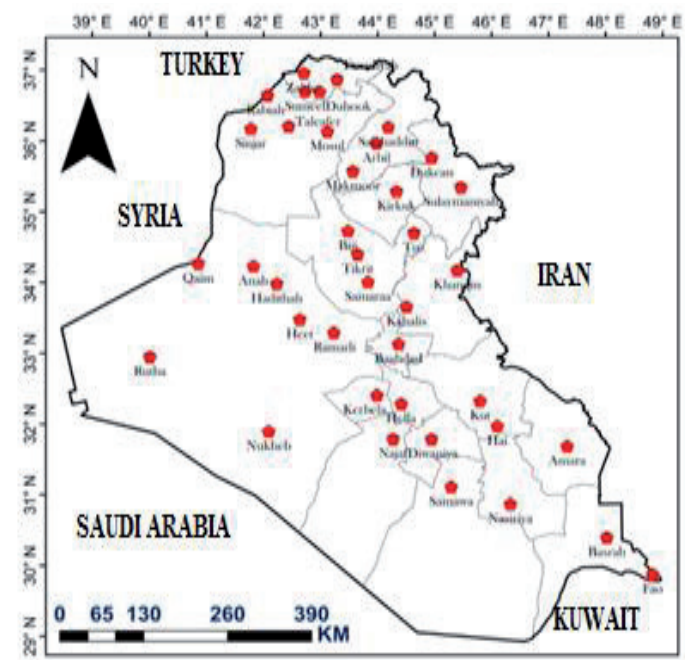

FIGURE 2. Locations of Iraqi stations

$$
r s=1-\frac{6 \sum_{i=1}^{n} d i^{2}}{n\left(n^{2}-1\right)}
$$

- probability value ( $p$-value)

Then calculating the amount of $\left(d_{i}\right)$ through $\left(d_{i}=k_{i}-i\right)$ where $(i)$ value ranging $I=1,2,3, \ldots, n$. Where $n$ is the number of measurements in each of the two varieties in the correlation, $d_{i}$ is the ranked difference between the $i^{\text {th }}$ measurements for the two varieties. In a statistical hypothesis test, the $p$-value is the level of marginal significance representing a given event's probability of occurrence. To calculate $p$-values, you can use $p$-value tables or spreadsheet/ /statistical software (Al-jaf \& Al-Taai, 2019a). A smaller $p$-value indicates that there is stronger evidence favoring the alternative hypothesis (Al-jaf \& Al-Taai, 2019b).

\section{Results and discussion}

The total yearly mean of CAPE, $C_{p}$ and $T_{p}$ over Iraq

Figure 3 shows the highest total yearly mean of CAPE, $\mathrm{C}_{\mathrm{p}}$ and $\mathrm{T}_{\mathrm{p}}$ over Iraq including northern stations as Dohook, Zakho, etc. This is due to meteorological factors, which include low temperatures, high humidity and low solar radiation. Which leads to the formation of many clouds and rain, which are accompanied by many different weather phenomena such as lightning, thunder, storms and hurricane. While the central and southern stations are characterized by high temperature and low humidity and the amount of solar radiation high, which leads to a decrease in the number of clouds and lack of rain as well as nature of the surface and to the nature of 
a

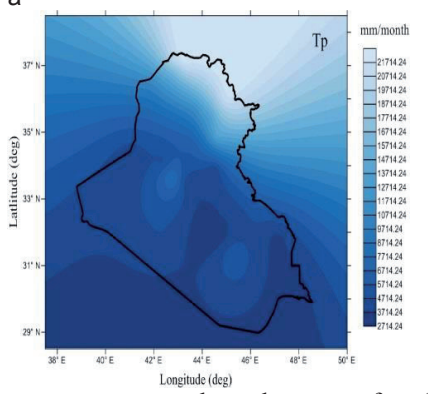

b

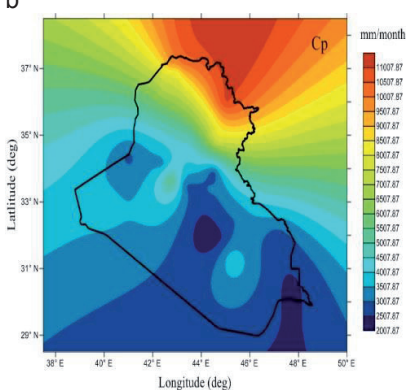

C

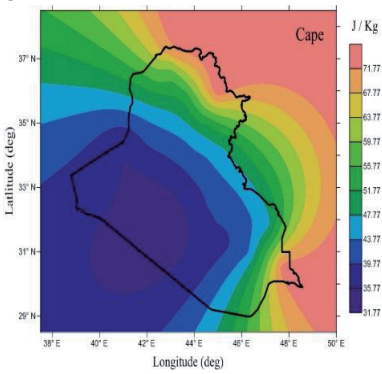

FIGURE 3. Total yearly mean of $\mathrm{T}_{\mathrm{p}}(\mathrm{a}), \mathrm{C}_{\mathrm{p}}$ (b) and CAPE (c) over Iraq for 30-year period, from 1989 to 2018

the various air masses that are blowing on the country, climate changes, air pressure systems, jet streams, the Mediterranean sea cyclone and the Sudanese cyclone. Which have an important role in the formation and rainfall? The amount of rain is important to improve weather and climate forecasting.

\section{The total monthly mean of CAPE, $C_{p}$ and $T_{p}$ over Iraq}

Figure 4 shows the total monthly mean of CAPE, $\mathrm{C}_{p}$ and $\mathrm{T}_{\mathrm{p}}$ over the Dohook station. It is seen that the behavior of rainfall with months oscillates between increase and decrease. Where the highest average 30 -year of the CAPE coefficient was during April and the lowest in July and August months.

The highest total 30-year of the $\mathrm{C}_{\mathrm{p}}$ coefficient was during March month and the lowest in July and August months. The highest total 30 -year of the $T_{p}$ coefficient was during January month and the lowest in July and August months. Increased rainfall in winter and early spring and autumn this due to increased frequency of medium atmospheric depressions and Sudanese cyclone, there is light rain at the early summer returning to the season Indian cyclone (thermal cyclone) and it dissolves in mid-summer.

Figure 5 shows the total monthly mean of CAPE, $\mathrm{C}_{\mathrm{p}}$ and $\mathrm{T}_{\mathrm{p}}$ over the Mosul station. It is seen that the behavior of rainfall with months oscillates between increase and decrease where the highest average 30-year of the CAPE coefficient was during April and the lowest in July and August months. The highest total 30-year of the $\mathrm{C}_{\mathrm{p}}$ coefficient was during March month and the lowest in July and August months.

The highest total 30-year of the $T_{p}$ coefficient was during January month and the lowest in July and August months. Increased rainfall in winter and early spring and autumn this due to increased frequency of medium atmospheric depressions and Sudanese cyclone, there is light rain at the early summer returning to the season Indian cyclone (thermal cyclone) and it dissolves in mid-summer.

Figure 6 shows the total monthly mean of CAPE, $C_{p}$ and $T_{p}$ over the Rabiah station. It is seen that the behavior of rainfall with months oscillates between increase and decrease where the highest average 30-year of the CAPE coefficient was during April and May while the lowest in July and August months. The high- 

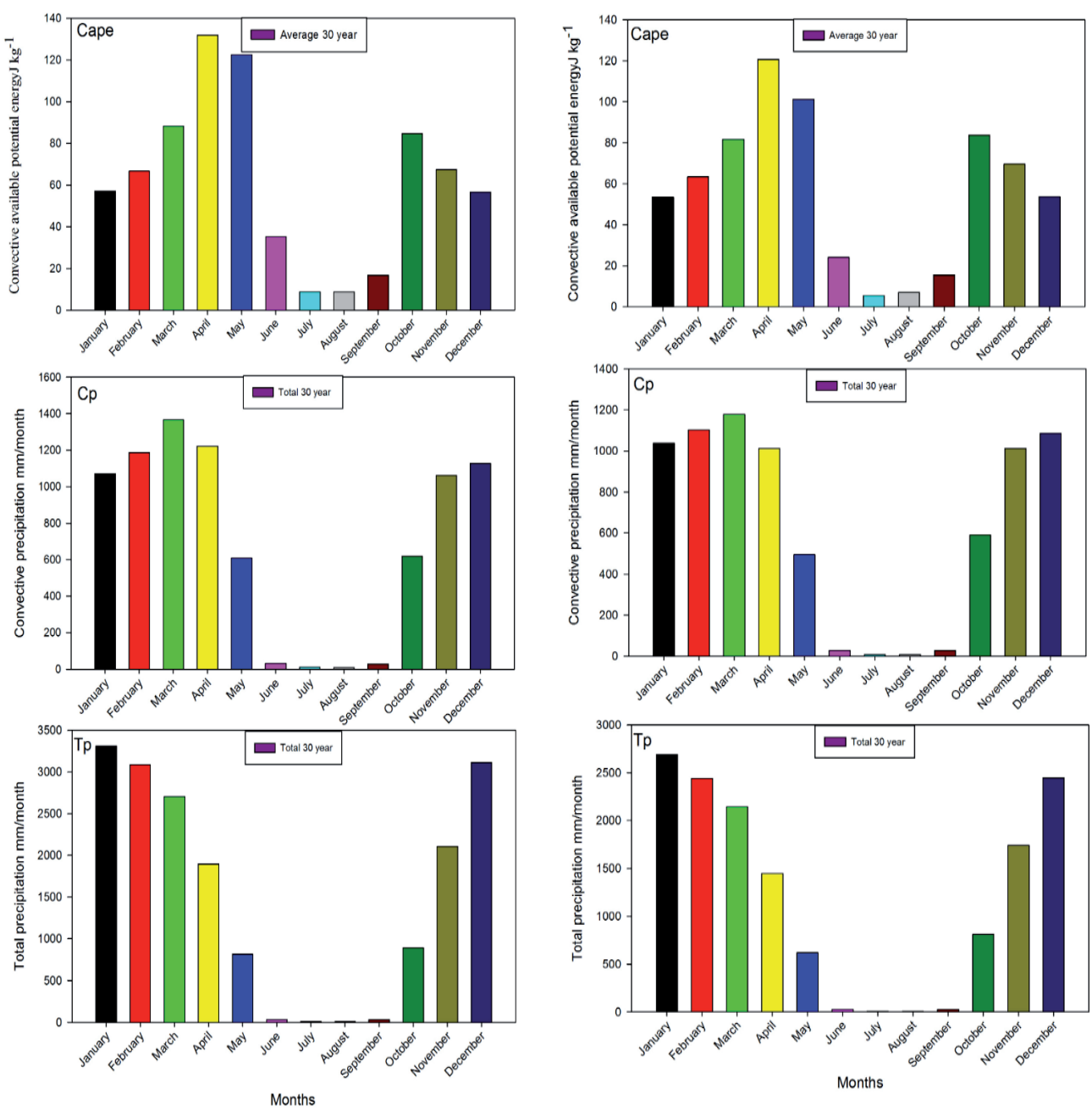

FIGURE 4. The total monthly mean of convective available potential energy $\left(\mathrm{J} \cdot \mathrm{kg}^{-1}\right)$, monthly convective precipitation $(\mathrm{mm})$ and total monthly precipitation $(\mathrm{mm})$ respectively by CAPE, $\mathrm{C}_{\mathrm{p}}$ and $\mathrm{T}_{\mathrm{p}}$ for Dohook station

est total 30-year of the $\mathrm{C}_{\mathrm{p}}$ coefficient was during March and December months and the lowest in July and August months. The highest total 30-year of the $\mathrm{T}_{\mathrm{p}}$ coefficient was during January and December months while the lowest in July and August months. Increased rainfall in

FIGURE 5. The total monthly mean of convective available potential energy $\left(\mathrm{J} \cdot \mathrm{kg}^{-1}\right)$, monthly convective precipitation $(\mathrm{mm})$ and total monthly precipitation $(\mathrm{mm})$ respectively by CAPE, $\mathrm{C}_{\mathrm{p}}$ and $\mathrm{T}_{\mathrm{p}}$ for Mosul station

winter and early spring and autumn this due to increased frequency of medium atmospheric depressions and Sudanese cyclone, there is light rain at the early summer returning the season Indian cyclone (thermal cyclone) and it dissolves in mid-summer. Figure 7 shows the total 

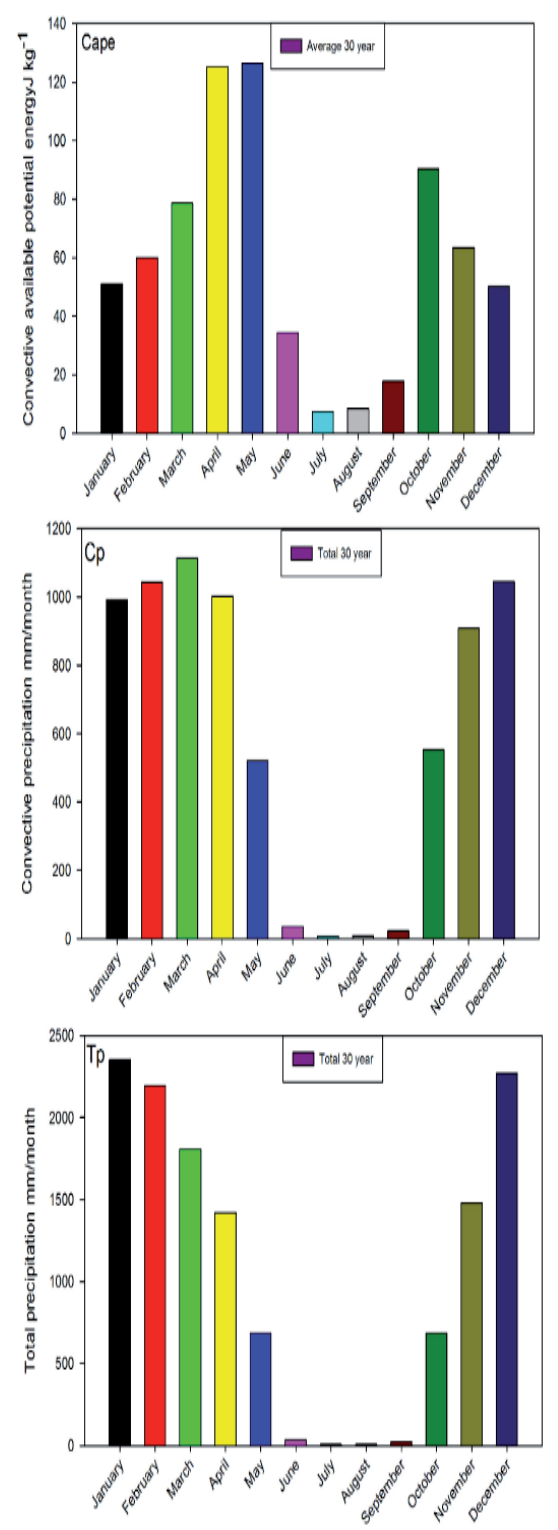

Months

FIGURE 6. The total monthly mean of convective available potential energy $\left(\mathrm{J} \cdot \mathrm{kg}^{-1}\right)$, monthly convective precipitation $(\mathrm{mm})$ and total monthly precipitation $(\mathrm{mm})$ respectively by CAPE, $\mathrm{C}_{\mathrm{p}}$ and $\mathrm{T}_{\mathrm{p}}$ for Rabiah station
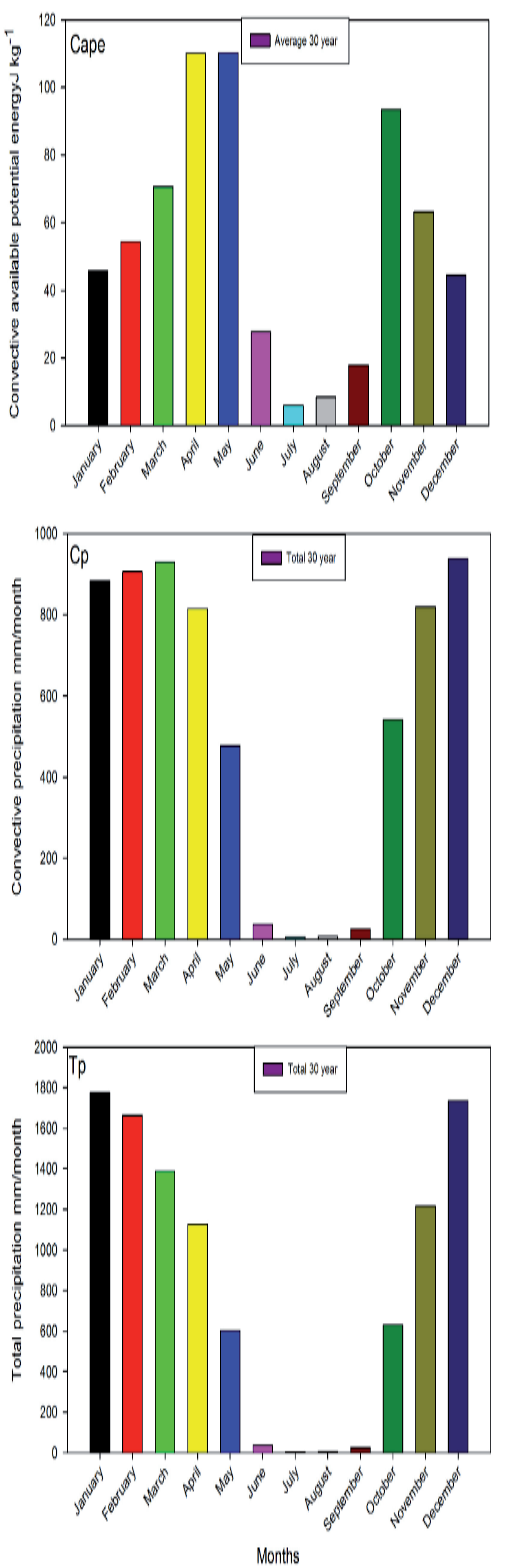

FIGURE 7. The total monthly mean of convective available potential energy $\left(\mathrm{J} \cdot \mathrm{kg}^{-1}\right)$, monthly convective precipitation $(\mathrm{mm})$ and total monthly precipitation $(\mathrm{mm})$ respectively by CAPE, $\mathrm{Cp}$ and $T_{p}$ for Sinjar station 
monthly mean of CAPE, $\mathrm{C}_{\mathrm{p}}$ and $\mathrm{T}_{\mathrm{p}}$ over the Sinjar station. It is seen that the behavior of rainfall with months oscillates between increase and decrease where the highest average 30-year of the CAPE coefficient was during April and May while the lowest in July and August months.

The highest total 30-year of the $\mathrm{C}_{\mathrm{p}}$ coefficient was during March and December months and the lowest in July and August months. The highest total 30-year of the $T_{p}$ coefficient was during January and December months while the lowest in July and August months. Increased rainfall in winter and early spring and autumn this due to increased frequency of medium atmospheric depressions and Sudanese cyclone, there is light rain at the early summer returning to the season Indian cyclone (thermal cyclone) and it dissolves in mid-summer. Figure 8 shows the total monthly mean of CAPE, $\mathrm{C}_{p}$ and $\mathrm{T}_{\mathrm{p}}$ over the $\mathrm{Za}$ kho station. It is seen that the behavior of rainfall with months oscillates between increase and decrease where the highest average 30-year of the CAPE coefficient was during April and may while the lowest in July and August months. The highest total 30-year of the $\mathrm{C}_{\mathrm{p}}$ coefficient was during March and April months and the lowest in July and August and September months. The highest total 30-year of the $T_{p}$ coefficient was during January and December months and the lowest in July and August months. Increased rainfall in winter and early spring and autumn this due to increased frequency of medium atmospheric depressions and Sudanese cyclone, there is light rain at the early summer returning to the season Indian cyclone (thermal cyclone) and it dissolves in mid-summer.
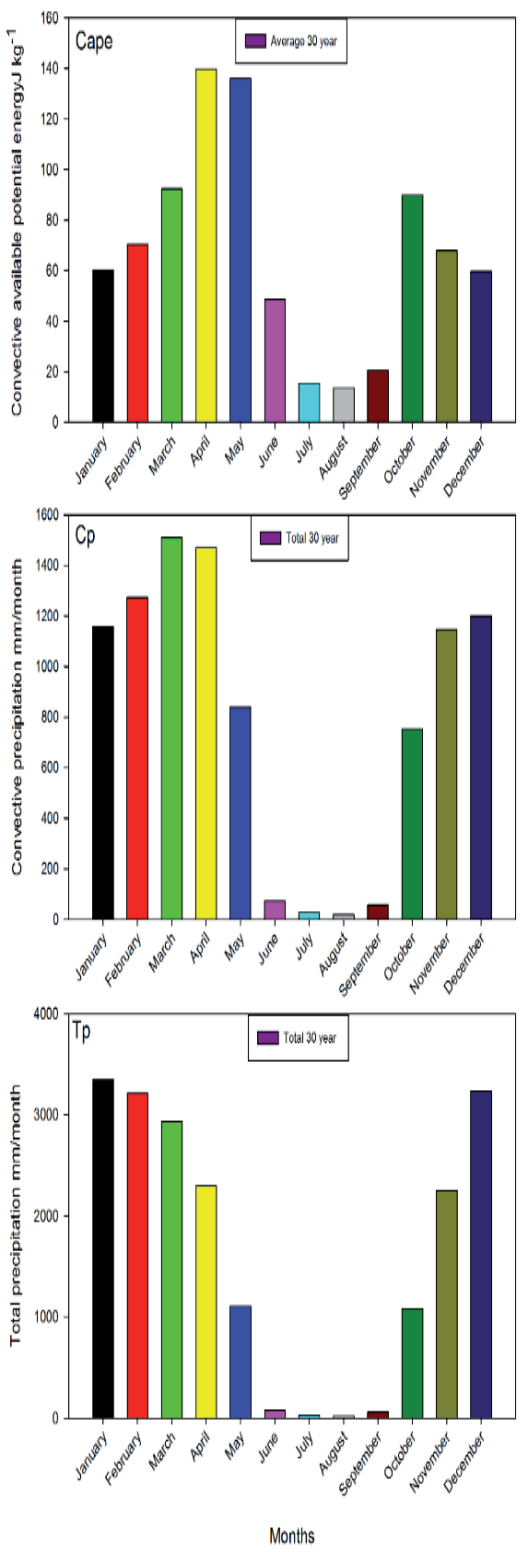

FIGURE 8. The total monthly mean of convective available potential energy $\left(\mathrm{J} \cdot \mathrm{kg}^{-1}\right)$, monthly convective precipitation $(\mathrm{mm})$ and total monthly precipitation ( $\mathrm{mm}$ ) respectively by $\mathrm{CAPE}, \mathrm{C}_{\mathrm{p}}$ and $\mathrm{T}_{\mathrm{p}}$ for Zakho station 
The total yearly mean of CAPE, $\mathrm{C}_{\mathrm{p}}$ and $T_{p}$ for the selected station over Iraq

Figure 9 shows the maximum yearly mean of CAPE, $\mathrm{C}_{\mathrm{p}}$ and $\mathrm{T}_{\mathrm{p}}$ over Dohook station respectively 101.9047 $\mathrm{J} \cdot \mathrm{kg}^{-1}$ for the 2006 year, $434.2045 \mathrm{~mm}$ for the 2018 year, $908.7591 \mathrm{~mm}$ for the 1992 year. The maximum yearly mean of CAPE, $\mathrm{C}_{\mathrm{p}}$ and $\mathrm{T}_{\mathrm{p}}$ over Mosul station respectively $96.84094 \mathrm{~J} \cdot \mathrm{kg}^{-1}, 410.1414$ $\mathrm{mm}, 718.0172 \mathrm{~mm}$ for the 2018 year. The maximum yearly mean of CAPE, $\mathrm{C}_{\mathrm{p}}$ and $\mathrm{T}_{\mathrm{p}}$ over Rabiah station respectively $106.2608 \mathrm{~J} \cdot \mathrm{kg}^{-1}$ for the year 2006 , $400.8977 \mathrm{~mm}, 692.3379 \mathrm{~mm}$ for the 2018 year. The maximum yearly mean of CAPE, $\mathrm{C}_{\mathrm{p}}$ and $\mathrm{T}_{\mathrm{p}}$ over Sinjar station respectively $100.6505 \mathrm{~J} \cdot \mathrm{kg}^{-1}$ for 2006 year, $377.1396 \mathrm{~mm}, 605.5202 \mathrm{~mm}$ for the
2018 year. The maximum yearly mean of CAPE, $\mathrm{C}_{\mathrm{p}}$ and $\mathrm{T}_{\mathrm{p}}$ over Zakho station respectively $106.8305 \mathrm{~J} \cdot \mathrm{kg}^{-1}$ for the 2006 year, $479.4777 \mathrm{~mm}$ for the 2018 year, $935.4565 \mathrm{~mm}$ for the 1992 year. Iraq is affected by the cyclone arrival of the Mediterranean Sea (rain is concentrated in northern regions) and the Sudanese cyclone (rain is concentrated in central and southern regions) this leading to precipitation, thunderstorms and changes in wind speed and direction, atmospheric pressure, temperature and humidity.

\section{The relationship between $\mathrm{CAPE}, \mathrm{C}_{\mathrm{p}}$ and $T_{p}$ for the selected station over Iraq}

Figure 10 shows the type of relationship and the strength of the correlation between meteorological parameters for
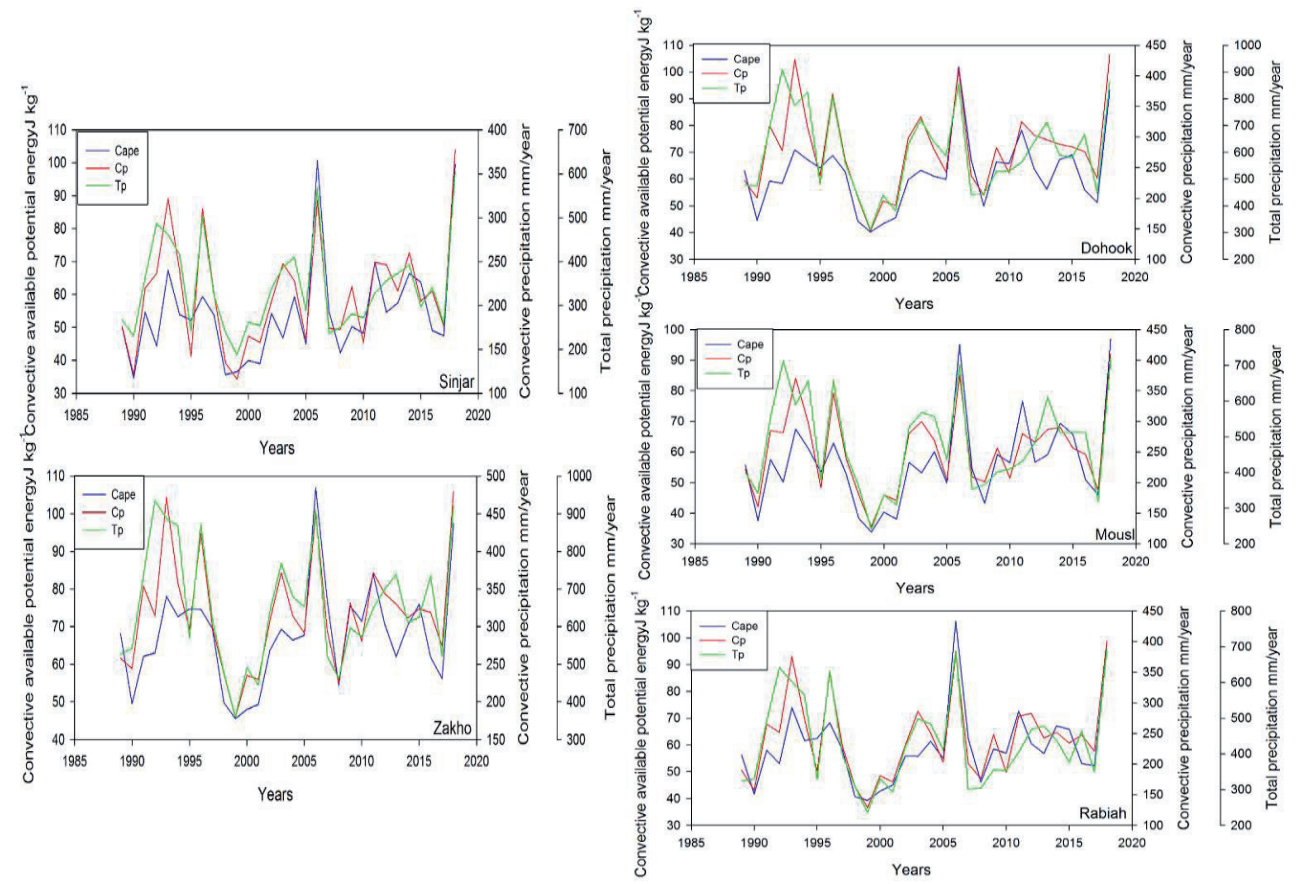

FIGURE 9. The yearly mean of CAPE, $\mathrm{C}_{\mathrm{p}}$ and $\mathrm{T}_{\mathrm{p}}$ data for selected stations 

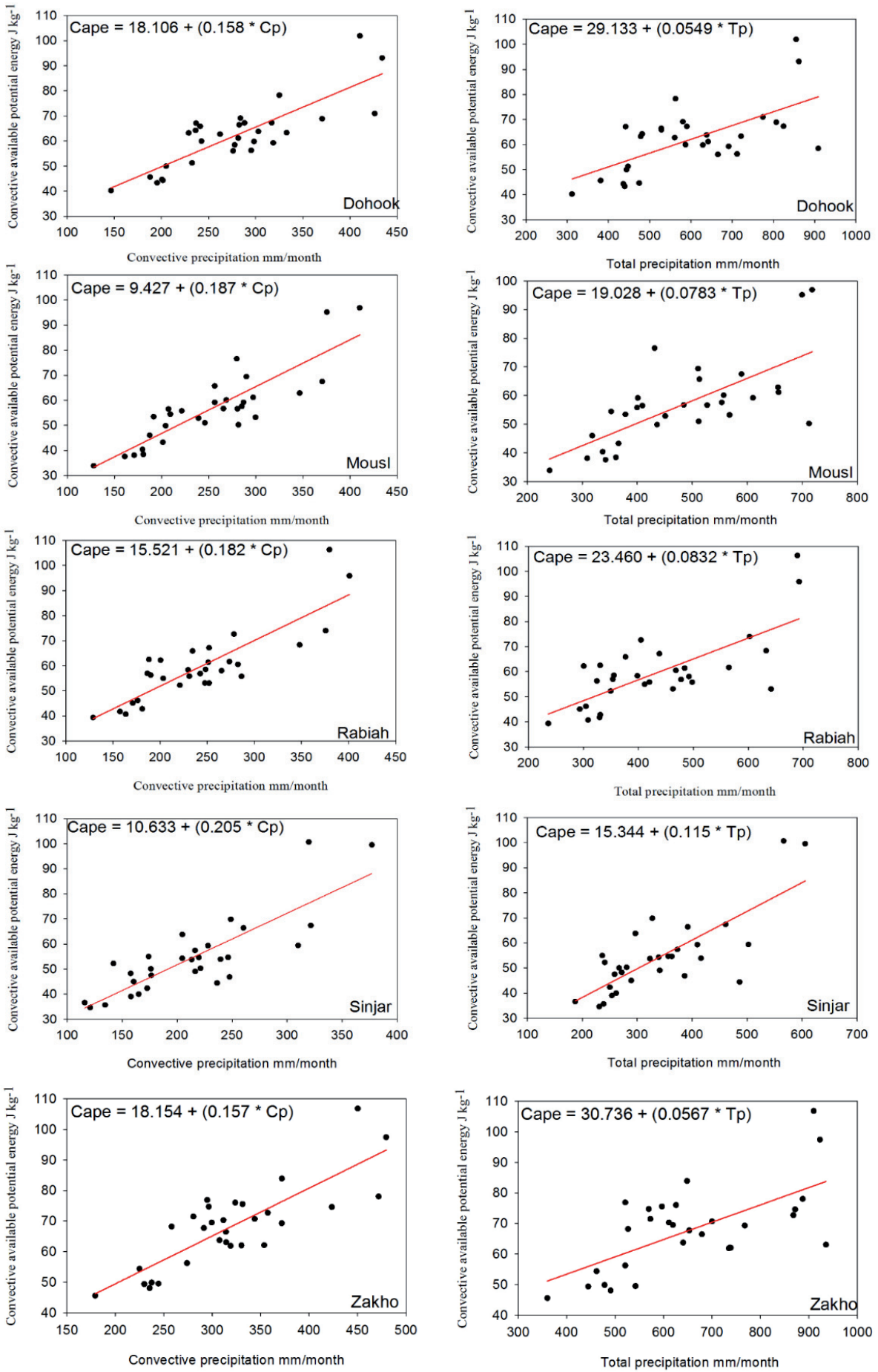

FIGURE 10. The relationship between CAPE, $\mathrm{C}_{\mathrm{p}}$ and $\mathrm{T}_{\mathrm{p}}$ data for selected stations 
selected station Dohook, Mosul, Rabiah, Sinjar and Zakho. Where the relationship between the convective available potential energy and the convective precipitation is positive and the relationship between the convective available potential energy and the total precipitation is positive too at all station but Mosul station represents very high correlation while Zakho station represents low correlation. This due to heating of ground surface when the land warms up, it heats the air above it. This causes the air to expand and rise. As the air rises, it cools and condenses this lead to form clouds and convective rainfall is often accompanied by lightning and thunder. Which makes the high correlation. However, Mosul has high heating but weak condensation, leading to fewer clouds and rains, thus rainfall depends on geographical location and nature of the region. Table 2 shows relationship between CAPE with $\mathrm{C}_{\mathrm{p}}$ and $\mathrm{T}_{\mathrm{p}}$ for the 30 years over Iraq.

\section{Conclusions}

- Iraq is characterized by a lack of rainfall and limited to winter mainly and the beginning of spring and autumn less degree this due to the increased frequency of medium atmospheric depressions but in spring and autumn are less rainy because the Mediterranean declines are losing their impact on Iraq and the region is under the influence of tropical continental air, which is characterized by drought. Thus, lead to increased drought and high evaporation due to the amount of solar radiation high especially in summer.

- Rain is increasing in the northern stations more than in the southern stations, where it gradually takes shape in the north. Rain falls more than the central stations where the central stations have more rain than the southern stations. This difference is due to

TABLE 2. The relationship between CAPE with $C_{p}$ and $T_{p}$ for the 30 years over Iraq

\begin{tabular}{|c|c|c|c|c|c|}
\hline \multicolumn{2}{|c|}{ Simple linear regression } & \multicolumn{3}{|c|}{ Spearman rho test } & \multirow[b]{2}{*}{ Station } \\
\hline $\begin{array}{l}\text { Interpretation } \\
\text { of relationship }\end{array}$ & $p$ & Correlation degree & $R_{S}$ & relation & \\
\hline linear relation & $<0.001$ & high positive correlation & 0.8 & CAPE vs $\mathrm{C}_{\mathrm{p}}$ & \multirow{2}{*}{ Dohook } \\
\hline linear relation & $<0.001$ & high positive correlation & 0.8 & CAPE vs $T_{p}$ & \\
\hline linear relation & $<0.001$ & high positive correlation & 0.9 & CAPE vs $\mathrm{C}_{\mathrm{p}}$ & \multirow{2}{*}{ Mosul } \\
\hline linear relation & $<0.001$ & high positive correlation & 0.7 & CAPE vs $T_{p}$ & \\
\hline linear relation & $<0.001$ & high positive correlation & 0.8 & CAPE vs $\mathrm{C}_{\mathrm{p}}$ & \multirow{2}{*}{ Rabiah } \\
\hline linear relation & $<0.001$ & high positive correlation & 0.6 & CAPE vs $T_{p}$ & \\
\hline linear relation & $<0.001$ & very high positive correlation & 0.8 & CAPE vs $\mathrm{C}_{\mathrm{p}}$ & \multirow{2}{*}{ Sinjar } \\
\hline linear relation & $<0.001$ & high positive correlation & 0.7 & CAPE vs $T_{p}$ & \\
\hline linear relation & $<0.001$ & middle positive correlation & 0.7 & CAPE vs $\mathrm{C}_{\mathrm{p}}$ & \multirow{2}{*}{ Zakho } \\
\hline linear relation & $<0.001$ & low positive correlation & 0.5 & CAPE vs $T_{p}$ & \\
\hline
\end{tabular}


the nature of the Earth's surface and the different air masses blowing on the country.

- The main reason for Iraq's rains during winter and spring is the Mediterranean Sea cyclone, Sudanese cyclone, convective clouds, instability, the pressure systems, meteorological factor, and airlifting mechanism, nature of the surface, various air masses, terrain and jet streams.

- The relationship between CAPE and $\mathrm{C}_{\mathrm{p}}$ is positive and the relationship between CAPE and $T_{p}$ is positive too at all station but Mosul station represents very high correlation while Zakho station represents low correlation this due to the nature of the region, airlifting mechanism, condensation and the meteorological factors.

- The Dohook station the maximum yearly mean of CAPE, $\mathrm{C}_{\mathrm{p}}$ and $\mathrm{T}_{\mathrm{p}}$ respectively $101.9047 \mathrm{~J} \cdot \mathrm{kg}^{-1}$ for the 2006 year, $434.2045 \mathrm{~mm}$ for the 2018 year, $908.7591 \mathrm{~mm}$ for the 1992 year.

- The Mosul station the maximum yearly mean of CAPE, $\mathrm{C}_{\mathrm{p}}$ and $\mathrm{T}_{\mathrm{p}}$ respectively $96.84094 \mathrm{~J} \cdot \mathrm{kg}^{-1}$, $410.1414 \mathrm{~mm}, 718.0172 \mathrm{~mm}$ for the 2018 year.

- The Rabiah station the maximum yearly mean of CAPE, $\mathrm{C}_{\mathrm{p}}$ and $\mathrm{T}_{\mathrm{p}}$ respectively $106.2608 \mathrm{~J} \cdot \mathrm{kg}^{-1}$ for the 2006 year, $400.8977 \mathrm{~mm}, 692.3379$ $\mathrm{mm}$ for the 2018 year.

- The Sinjar station the maximum yearly mean of CAPE, $\mathrm{Cp}$ and $\mathrm{T}_{\mathrm{p}}$ respectively $100.6505 \mathrm{~J} \cdot \mathrm{kg}^{-1}$ for 2006 year, $377.1396 \mathrm{~mm}, 605.5202 \mathrm{~mm}$ for the 2018 year.

- The Zakho station the maximum yearly mean of CAPE, $C_{p}$ and $T_{p}$ respectively $106.8305 \mathrm{~J} \cdot \mathrm{kg}^{-1}$ for the 2006 year, $479.4777 \mathrm{~mm}$ for the 2018 year, $935.4565 \mathrm{~mm}$ for the 1992 year.

- The Zakho station of Iraq has the highest total monthly mean of CAPE accompanied by the highest convective and total precipitation.

\section{Acknowledgements}

An acknowledgement to the European Center Medium Weather Forecasts (ECMWF) on the data used in this study as well as an acknowledgement to the Mustansiriyha University.

\section{References}

Abbood, Z.M. \& Al-Taai, O.T. (2018a). Calculation of absorption and emission of thermal radiation by clouds cover. ARPN Journal of Engineering and Applied Sciences, 13(24), 9446-9456.

Abbood, Z.M. \& Al-Taai, O.T. (2018b). Study of absorbance and emissivity solar radiation by clouds, aerosols and some atmospheric gases. Journal of Applied and Advanced Research, 3(5), 128-134.

Ahrens, C.D. (2013). Meteorology today: an introduction to weather, climate and the environment. 10th ed. Belmont, CA: Brooks/Cole.

Al-jaf, S.J. \& Al-Taai, O.T. (2019a). Impact of nitrous oxide $\left(\mathrm{N}_{2} \mathrm{O}\right)$ concentrations on atmospheric air temperature changes over Iraq and some neighboring regions. Journal of the University of Garmian, 6(1), 338-343.

Al-jaf, S.J. \& Al-Taai, O.T. (2019b). Impact of carbon dioxide concentrations on atmospheric temperature changes over Iraq and some neighboring countries. Plant Archives, 19(2), 1450-1456.

Al-Obeidi, A.M. (2008). The effect of rainfall on soil erosion for selected station in Iraq (PhD thesis, Mustansiriyah University Baghdad, Iraq).

Al-Timimi, Y.K. (2012). Assessment of drought in Iraq using Standardized Precipitation Index 
(SPI) and satellite data (PhD thesis, Mustansiriyah University Baghdad, Iraq).

Bolboaca, S.D. \& Jäntschi, L. (2006). Pearson versus Spearman, Kendall's tau correlation analysis on structure-activity relationships of biologic active compounds. Leonardo Journal of Sciences, 5(9), 179-200.

Doswell III, C.A. \& Rasmussen, E.N. (1994). The effect of neglecting the virtual temperature correction on CAPE calculations. Weather and Forecasting, 9(4), 625-629. DOI 10.1175/1520-0434(1994)009<0625: TEONTV $>2.0 . \mathrm{CO} ; 2$

Gabler, R.E., Petersen, J.F., Trapasso, L.M. \& Sack, D. (2009). Physical geography. 9th ed. Belmont, CA: Brooks/Cole.

Gettelman, A. Seidel, D. Wheeler, M. \& Ross, R. (2002). Multidecadal trends in tropical convective available potential energy. Journal of Geophysical Research Atmospheres, 107(D-21), ACL-17. DOI 10.1029/2001JD001082

Goyal, M.K. (2016). Engineering hydrology. Delhi: PHI Learning.

Hron, K., Filzmoser, P. \& Thompson, K. (2012). Linear regression with compositional explanatory variables. Journal of Applied Statistics, 39(5), 1115-1128.

Lackmann, G. (2013). Midlatitude synoptic meteorology. Chicago: The University of Chicago Press.

Meukaleuni, C., Lenouo, A. \& Monkam, D. (2016). Climatology of convective available potential energy (CAPE) in ERA - interim reanalysis over West Africa. Atmospheric Science Letters, 17(1), 65-70.

Namdar, K.H. (2017). Synoptic study of role of convective available potential energy on formation rainstorm over Iraq (master's thesis, Mustansiriyah University Baghdad, Iraq).

Niwas, R., Singh, S., Singh, D., Khichar, M.L. \& Singh, R. (2006). A textbook on agricultural meteorology. Research Gate.

Padua, D. (2000). The Fortran I compiler. Computing in Science and Engineering, 2(1), 70-75.

Riemann-Campe, K., Fraedrich, K. \& Lunkeit, F. (2009). Global climatology of convective available potential energy (CAPE) and convective inhibition (CIN) in ERA-40 reanalysis. Atmospheric Research, 93(1-3), 534-545.
Salman, A.D. (2015). The effect of temperature and rainfall on crop productivity of wheat and barley in some governorates of Iraq (master's thesis, Mustansiriyah University Baghdad, Iraq).

Saxena, R.N. \& Gupta, D.C. (2017). Elements of hydrology and groundwater. Delhi: PHI Learning.

Schultz, P. (1989). Relationships of several stability indices to convective weather events in northeast Colorado. Weather and Forecasting, 4(1), 73-80.

Wang, P.K. (2013). Physics and dynamics of clouds and precipitation. Cambridge: Cambridge University Press.

York, D., Evensen, N.M., Martýnez, M.L. \& Delgado, J.D. (2004). Unified equations for the slope, intercept, and standard errors of the best straight line. American Journal of Physics, 72(3), 367-375.

Zakaria, S., Al-Ansari, N., Ezz-Aldeen, M. \& Knutsson, S. (2012). Rainwater harvesting at eastern Sinjar Mountain, Iraq. Geoscience Research, 3(2), 100-108.

\section{Summary}

Analysis of the convective available potential energy by precipitation over Iraq using ECMWF data for the period of 1989-2018. The Convective Available Potential Energy (CAPE) represents the amount of energy for a sample of air. The sample departs vertically within the atmosphere and through these values the potential energy to predict the extreme weather conditions such as storms, hurricanes, lightning and thunder. Data are taken by CAPE, convective precipitation $\left(\mathrm{C}_{\mathrm{p}}\right)$ and total precipitation $\left(\mathrm{T}_{\mathrm{p}}\right)$ from satellites recorded by the European Centre for Medium-Range Weather Forecasts (ECMWF). The choice of 30 years (1989-2018) over Iraq station between two latitudes $\left(29.5^{\circ}-37.22^{\circ} \mathrm{N}\right)$ and two longitudes $\left(48.45^{\circ}-38.45^{\circ} \mathrm{E}\right)$. Otherwise, we have studied total yearly mean of CAPE, $C_{p}$ and $T_{p}$ over Iraq, the total monthly mean of CAPE, $\mathrm{C}_{\mathrm{p}}$ and $\mathrm{T}_{\mathrm{p}}$ for the selected station, as well as 
the relationship between of CAPE, $\mathrm{C}_{\mathrm{p}}$ and $\mathrm{T}_{\mathrm{p}}$ for the selected station. The results showed that the highest total yearly mean of CAPE, $\mathrm{C}_{\mathrm{p}}$ and $\mathrm{T}_{\mathrm{p}}$ over Iraq was included northern stations and lowest was included central and southern stations. The highest total monthly mean of CAPE, $\mathrm{C}_{\mathrm{p}}$ and $\mathrm{T}_{\mathrm{p}}$ for Zakho station. The relationship between the CAPE and $\mathrm{C}_{\mathrm{p}}$ is positive and the relationship between CAPE and $T_{p}$ is positive too at five stations but Mosul station represents very high correlation while Zakho station represents the low correlation.

\section{Authors' address:}

Osama T. Al-Taai

(http://orcid.org/0000-0002-4747-214X)

Zainab M. Abbood

(https://orcid.org/0000-0003-4005-2510)

Mustansiriyah University

College of Science

Atmospheric Science Department

Baghdad, Iraq

e-mail: osamaaltaai77@uomustansiriyah.edu.iq zainabatmo@uomustansiriyah.edu.iq 